\title{
Characterization of Natural Zeolite and Chicken Manure Derived Biochar for Carbon Dioxide Adsorption in Biogas
}

\author{
Margaretha Arnita Wuri ${ }^{1}$, Ambar Pertiwiningrum ${ }^{2,}$, Rachmawan Budiarto ${ }^{3}$, and Cahyono Agus Dwi Koranto ${ }^{4}$ \\ ${ }^{1}$ Master Program of Technology for Sustainable Development, Universitas Gadjah Mada, Indonesia \\ ${ }^{2}$ Faculty of Animal Science, Universitas Gadjah Mada, Indonesia \\ ${ }^{3}$ Faculty of Engineering, Universitas Gadjah Mada, Indonesia \\ ${ }^{4}$ Faculty of Forestry, Universitas Gadjah Mada, Indonesia
}

\begin{abstract}
Although biogas is clean and environmentally friendly, its existence is often unsustainable, especially in rural area. Consumption of fossil fuel energy still dominates because cheaper, higher in energy efficiency and ready to use than biogas. One of the efforts to make biogas can compete with fossil fuel energy is by increasing calorific value. Reduction of carbon dioxide by adsorption enhances the calorific value that evidenced by methane enrichment. In this study, we investigated the effect three types of combined adsorbent: pure natural zeolite (Z-Z), zeolite-biochar from chicken manure (Z-B1) and zeolite-modified biochar (Z-B2) on methane content. The result showed that adsorption of biogas using Z-Z, Z-B1 and Z-B2 increased methane level with enhancement of 1,$36 ; 28,92$; and $11,27 \%$ respectively compared before adsorption. To confirm whether these results were influenced by adsorbent's character or not as consequence adsorbent characterization have been done in this study.
\end{abstract}

\section{Introduction}

Today global warming becomes the global disaster that threats all countries. The cause of global warming is the continuous increase of green house gases (GHGs), carbon dioxide, methane and dinitrogen oxide in the atmosphere. The increase of GHGs has been observed by National Oceanic and Atmospheric Administration (NOAA) since 1958 and the peak at 2016 [1]. Moreover, methane and dinitrogen oxide showed the same phenomenon [2]. As a matter of fact, methane and dinitrogen oxide have 21 times and 300 times greater potency than carbon dioxide to cause global warming. Some reports said that total methane and dinitrogen oxide in atmospheric are $10-12 \%$ of global GHG emissions. These emissions are dominated by agriculture and livestock sectors [3-5].

The fact becomes driving force renewable energy, for example, biogas technology. Biogas is able to isolate GHG emissions from anaerobic decomposition of agriculture and livestock waste and convert it directly into energy [6]. Although biogas has benefits in mitigating GHGs and overcoming the waste issue, implementation of biogas technology is often unsustainable. Lower calorific value of biogas becomes one of the barriers in developing of biogas technology.
The decrease calorific value is caused by the present non-CH4 gases especially $\mathrm{CO} 2$ [7-8].

An innovation to improve calorific value is through biogas purification. Biogas purification is methane enrichment method by separating methane from decreasing calorific value gases [9]. The other methods of biogas purification such as water scrubbing, cryogenic, membrane separation, chemical absorption and adsorption have been developed and evaluated [7-8]. But in a rural area, a cheap, simple and viable method becomes more attractive so that implementation can be sustainable [9]. Adsorption becomes the most choosable option to be selected because adoptable and inexpensive [10].

In this study, we investigated the effect of combinations adsorbent, natural zeolite and chicken manure-derived biochar against methane enrichment in biogas. Zeolite has good performance in carbon dioxide adsorption [11] but zeolite has a drawback that no every rural area have natural zeolite resources. As consequence, adsorbent cost becomes expensive because of packaging and distribution process. Biochar has been purposed as a substitute adsorbent for partial natural zeolite due to low cost and environmental friendly [1213]. Surface modification on biochar was also carried out in this study to improve $\mathrm{CO}_{2}$ adsorption capability [14-15].

\footnotetext{
Corresponding author: artiwi@mail.ugm.ac.id
} 


\section{Methodology}

\subsection{Materials}

Natural zeolite with an average particle size between 1-3 $\mathrm{mm}(\mathrm{Z})$ and ammonia solution from Bratachem. Natural zeolite pretreated by calcinating at $255 \mathrm{C}$ for 3 hours. Chicken manure for biochar production was supplied from PT. Charoend Phokpand. Ammonia solution 25\% was dissolved into $10 \% \mathrm{v} / \mathrm{v}$ for modification of biochar. Biogas was supplied by Gama Biogas, Agrotechnology Innovation Center, UGM.

\subsection{Synthesis of biochar and its modification}

After being dried by aeration for the full day, chicken manure was pyrolyzed at $500 \mathrm{C}$ under $\mathrm{N}_{2}$ atmosphere for 4 hours (B1). Modification of biochar was done by immersed biochar in ammonia solution $10 \%(\mathrm{v} / \mathrm{v})$ for 24 hours. Then the mixture was separated and oven dried at $105^{\circ} \mathrm{C}$ for 4 hours (B2).

\subsection{Characterization of Adsorbents}

Surface area, total pores volume and pore size were determined by Surface Area Analyzer (SAA). Pores surface area was determined by nitrogen $\left(\mathrm{N}_{2}\right)$ adsorption isotherms at $77 \mathrm{~K}$. by calculating using BraunauerEmmett-Teller (BET) method. Total pores volume were calculated from the amount $\mathrm{N}_{2}$ adsorption at the relative pressure of 0,99 . Biochars that produced from chicken manure and its modification were characterized using infrared (IR) spectroscopy with the potassium bromide $(\mathrm{KBr})$ technique. Sample preparation as $\mathrm{KBr}$ pellets by mixing samples with $\mathrm{KBr}$ at 1,3-1,5 wt\% using ball mill. The FTIR spectra scanned range of $4000-400 \mathrm{~cm}^{-1}$.

\subsection{Biogas Purification by Adsorption}

The experimental for adsorption test consists of two interconnected fix bed columns that filled 80 grams adsorbents for each column. The mass ratio of the adsorbent of 1:1 (40 grams:40 grams) in each column. Details of the formulation of adsorbents given in Table 1.

Table 1. Combinations of adsorbent

\begin{tabular}{|c|c|c|}
\hline Code & $\begin{array}{c}\text { 1" column } \\
\mathbf{( 4 0 : 4 0} \text { grams) }\end{array}$ & $\begin{array}{c}\mathbf{2}^{\text {nd }} \text { column } \\
\mathbf{( 4 0 : 4 0} \text { grams })\end{array}$ \\
\hline Z-Z & Natural zeolite & Natural zeolite \\
\hline Z:B1 & $\begin{array}{c}\text { Natural zeolite : } \\
\text { biochar }\end{array}$ & $\begin{array}{c}\text { Natural zeolite : } \\
\text { biochar }\end{array}$ \\
\hline Z:B2 & $\begin{array}{c}\text { Natural zeolite : } \\
\text { modified biochar }\end{array}$ & $\begin{array}{c}\text { Natural zeolite : } \\
\text { modified biochar }\end{array}$ \\
\hline
\end{tabular}

For adsorption process, the first column was connected to the compressor which related to biogas holder from Gama Biogas and the other column was connected to the tapping biogas holder. The adsorption process was done at a gas pressure ranging 2 to $7 \mathrm{~kg} / \mathrm{cm}^{2}$. To know the effect of adsorbent against methane composition, biogas before and after adsorption were analyzed with gas chromatography.

\section{Results and Discussion}

\subsection{Adsorbent Characteristics}

The surface area of natural zeolite was calculated from $\mathrm{N}_{2}$ adsorption isotherms using Braunauer-Emmett-Teller (BET) method. Natural zeolite had the specific surface area of $27,9 \mathrm{~m} / \mathrm{g}$. Pores consisted mainly mesopores and dominated size pores of $2,67 \mathrm{~nm}$. Fig. 1. showed $\mathrm{N}_{2}$ sorption isotherms curve of natural zeolite. The curve exhibited type III according to International of Pure Applied and Chemistry (IUPAC) classification. The weak interaction between adsorbents and adsorbate made curve rose slightly at low relative pressure. When molecules have begun adsorped, the interaction between adsorbate get stronger and accelerated the rising curve at high relative pressure. It concluded that at high pressure is related to the higher loading of adsorbate on the natural zeolite. Fig. 1. showed that volume of $\mathrm{N}_{2}$ was adsorbed and desorbed on pores of natural zeolite almost same. It means natural zeolite can adsorb reversibly and has potential to be used for several adsorption processes with regeneration [16].

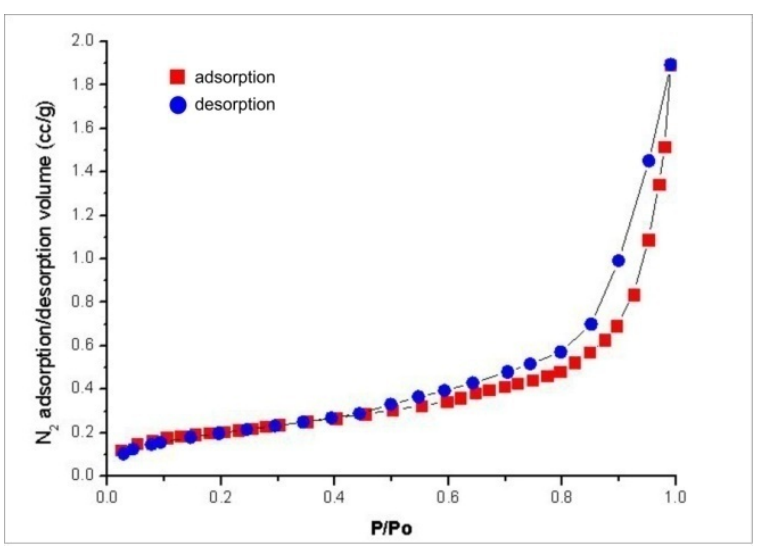

Fig. 1. $\mathrm{N}_{2}$ adsorption-desorption isotherm on natural zeolite

To investigate effect surface modification on the chemical characteristic of adsorbents, biochar and modified biochar (B1 and B2) were characterized using infrared (IR) spectroscopy. Spectrum at Fig. 2. showed no significant difference between B1 and B2. Even it presented some similarities of typical bands. The bands between $3440-3457 \mathrm{~cm}^{-}$confirmed vibration of $\mathrm{O}-\mathrm{H}$ stretching of phenol, alcohol, and carboxylic acid on the surface of biochar [17-18]. The vibration of $\mathrm{C}=\mathrm{C}$ aromatic stretching was identified at $1400-1500 \mathrm{~cm}^{-1}$. The peak represented $\mathrm{C}-\mathrm{O}$ from alcohol and $\mathrm{C}-\mathrm{C}$ aromatic bending confirmed at 1000-1200 and 873-875 cm. respectively [19]. 


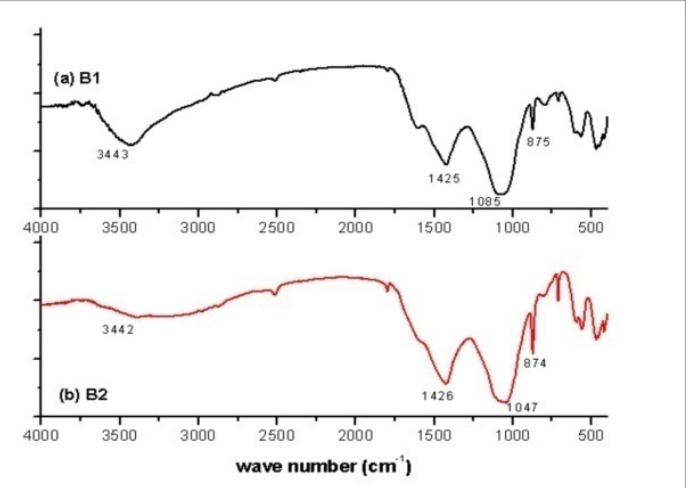

Fig. 2. IR Spectra (a) B1, biochar and (b) B2, modified biochar

\subsection{Biogas purification}

So far investigation effect combinations of adsorbent against methane composition in biogas, adsorption process have been done. Table 2. represents methane composition before and after adsorption.

Table 2. Methane composition in biogas before and after adsorption

\begin{tabular}{|c|c|c|c|}
\hline \multirow{2}{*}{ Code } & \multicolumn{2}{|c|}{$\begin{array}{c}\text { Methane composition } \\
(\boldsymbol{\%})\end{array}$} & $\begin{array}{c}\text { Enhancement } \\
(\boldsymbol{\%})\end{array}$ \\
\cline { 2 - 3 } & Before & After & \\
\hline Z-Z & 42,5 & 43,8 & 1,36 \\
\hline Z-B1 & 25,35 & 32,68 & 28,92 \\
\hline Z-B2 & 32,56 & 36,23 & 11,27 \\
\hline
\end{tabular}

In this study, biogas was considered composed of methane and the remaining carbon dioxide since the other gases composition were very small [20]. The decrease of carbon dioxide by adsorption was known from an enhancement in methane content. Methane composition in raw biogas fluctuated between 25 to $42,5 \%$. After adsorption with contact time for 10 minutes, methane content in purified biogas was analyzed. The best result in carbon dioxide adsorption was performed by combination adsorbent Z-B1 with a methane enrichment level of $28,92 \%$, followed by Z-B2 and Z-Z at $11,27 \%$ and $1,36 \%$ respectively.

The result from Table 2. was explained in this paper. Carbon dioxide adsorption on natural zeolite performed lowest methane enrichment. However, according to some reports zeolite showed better performance [11,19] than biochar. Adsorption is affected by the specific surface area where the higher specific surface area, more the number of adsorbate. But in this study natural zeolite has a low specific surface area of $27,9 \mathrm{~m}^{2} / \mathrm{g}$, smaller than surface area that reported by Hauchhum and Mahanta, and Alonso-Vicaro [11,22]. The absence of further activation was indicated micropore cavity clogged by impurities that should be dissolved during thermal activation. These clogged pores could not facilitate carbon dioxide adsorption that related to the low methane enhancement. It is also possibly caused by the presence of considerable moisture content in biogas inhibited the carbon dioxide capture because it competes with carbon dioxide in adsorption on zeolite [23].

In this study, substitution of some zeolite with biochar $(50 \%$ of total mass) can increase methane content in biogas. Biochar is composed of hollow aromatic carbon strictures [24] which can capture carbon dioxide molecules. To confirm the effect of the effectiveness of specific surface area on methane enrichment compared to zeolite, SAA analysis is also required. In addition, biochar is not sensitive to water vapor [18] compared with natural zeolite so in this study was indicated that the absence of capturing competition between water vapor and carbon dioxide on biochar. $\mathrm{Xu}$, et al. [25] also reported that biochar derived from livestock manure are rich in minerals which can facilitate carbon dioxide capture. the content of alkali metals such as $\mathrm{K}, \mathrm{Na}, \mathrm{Ca}$ and $\mathrm{Mg}$ increase the alkalinity of biochar. Based on Lewis acid-base theory, carbon dioxide is acidic molecule so that when biogas is passed through biochar then carbon dioxide will be adsorbed on biochar's pores and formed weak interaction with biochar [26]. This is the reason why partial replacement of natural zeolite with biochar actually raised methane level to the greatest of $28,92 \%$ during 10 minutes of contact time.

Surface modification with doping nitrogen can increase the alkalinity of biochar so that improve the capability of carbon dioxide capture on biochar [13-14] but the contrasting result from previous authors was also reported in this paper. In this study, methane enrichment by adsorption with Z-B2 was smaller $(11,27 \%)$ than adsorption using combination adsorbent Z-B1 with unmodified biochar $(28,92 \%)$. The lower methane enrichment of this sample than Z-B1 indicated that incorporation of nitrogen groups on biochar's surface didn't cause an increment capacity of carbon dioxide adsorption. It was caused some pore partially blockage by ammonia. The fact was evidenced from FTIR spectra of B2 that there is no new functional group formed (Fig. 2). Shafeeyan, et al. [27] also demonstrated that introduction of base functional at room temperature can lead to decrease micropore volume as consequence lowered carbon dioxide adsorption and then lowered methane enrichment. Formation of nitrogen-containing functional groups on biochar's surface required heat treatment. Heat treatment in doping nitrogen plays important role in the formation of free radicals from ammonia so that interaction between free radicals and carboxylic sites on biochar occurred and formed base functional groups [17].

\section{Conclusion}

Carbon dioxide adsorption in biogas that was represented by methane level was conducted using combinations of adsorbent. Although many authors claimed that zeolite has good performance in carbon dioxide but in this study, natural zeolite demonstrated 
the worst performance. Surface modification on biochar was not synthesized successfully. It can be confirmed from the result of adsorption using Z-B2 that perform lower methane enhancement than Z-B1. Heat treatment is required in surface modification on the biochar. The highest percentage of methane enhancement were $28,92 \%$ that performed by Z-B1. Based on this findings, chicken manure-derived biochar can be used an alternative adsorbent for carbon dioxide removal in biogas. Before implementation in a rural area, optimization of adsorption with chicken manure-derived biochar should be done.

This study was supported financially by grant funding from Graduate School, Universitas Gadjah Mada, Indonesia.

\section{References}

1. D. Dlugokencky, P. Tans, Trends in Atmospheric Carbon Dioxide: Recent Global $\mathrm{CO}_{2}$, $<$ https://esrl.noaa.gov/gmd/ccgg/trends/global.html $>$ (2004)

2. J. H. Buttler, S. A. Montzka, The NOAA Annual Greenhouse Gas Index (AGGI), $<$ https://esrl.noaa.gov/gmd/aggi/aggi.html> (2016)

3. P. Smith, D. Martino, Z. Cal, D. Gwary, H. Janzen, P. Kumar, B. McCarl, S. Ogle, F. O’Mara, C. Rice, B. Scholes, O. Sirotenko, Agriculture in Climate Change 2007: Mitigation (Cambridge University Press, Cambridge, 2007)

4. F. N. Tubiello, R. D. C. Golec, A. Ferrara, S. Rossi, R. Biancalani, S. Federici, H. Jacobs, A. Flammini, Agriculture, Forestry and Other Land Use Emissions by Sources and Removals by Sink: 19902011 (FAO, Rome, 2014)

5. IPCC (Intergovernmental Panel on Climate Change), Climate Change 2014: Mitigation of Climate Change Contribution of Working Group III to the Fifth Assessment Report (Cambridge University Press, Cambridge, 2014)

6. A.D. Cuellar, M. E. Webber, Env. Res. Lett 14 (2008) 1-8

7. Q. Sun, H. Li, J. Yan, L. Liu, Z. Yu, X. Yu, Renew. and Sustainable Energy Reviews 51 (2015) 521-532

8. W. M. Buszianowski, Renew. and Sustainable Energy Reviews 54 (2016) 1148-1171

9. M. R. A. Mamun, M. R. Karim, M. M. Rahman, A. M. Asiri, S. Torri, J. of The Taiwan Institute of Chem. Eng. 58 (2016) 476-481

10. B. Boulinguiez, P. L. Cloirec, Energy Fuels 24 (2010) 4756-4765

11. L. Hauchhum, P. Mahanta, Inter. J. of Energy, Env. and Eng. 5, 4(2014) 349-356

12. F. Lian, G. Cui, Z. Liu, L. Duo, G. Zhang, B. Xing, J. of Env. Management 176 (2016) 61-68

13. H. A. Alhashimi, C. B. Aktas, Res., Conversation and Recycling 118 (2017) 13-26
14. X. Zhang, S. Zhang, H. Yang, Y. Feng, Y. Chen, X. Wang, H. Chen, Chem. Engineering J. 257 (2014) 20-27

15. M. V. Nguyen, B. K. Lee, Process, Safety and Env. Protec. 104 (2016) 490-498

16. E. Wibowo, M. Rokhmat, Sutisna, Khairurrijal, M. Abdullah, Desalination 409 (2017)

17. A. Heidari, H. Younesi, A. Rashidi, A. A. Ghoreyshi, Chem. Eng. J. 254 (2014)

18. Y. Huang, P. Chiueh, C. Shih, S. Lo, L. Sun, Y. Zhong, C. Qiu, Energy 84 (2015)

19. M. Stefaniuk, P. Oleszcuk, J. of Analytical and Applied Pyrolysis 115 (2015)

20. P. J. Jorgensen, Biogas-Green Energy (Digisource Danmark A/S, Aarhus, 2015)

21. D. P. Bezerra, R. S. Oliveira, R. S. Vieira, C. L. Cavalcante Jr., D. C. S. Azevedo, Adsorption 17 (2011) 235-246

22. A. Alonso-Vicaro, J. R. Ocha-Gomez, S. G. Gil-Rio, O. Gomez-Jimenez-Aberasturi, C. A. RamirezLopez, J. Torrecilla-Soria, A. Dominguez, Microporous and Mesoporous Mater. 134 (2010) 100-107

23. D. Bonenfant, M. Kharoune, P. Niquette, $M$. Mimeault, R. Hausler, Sci. Technol. Adv. Mater 9 (2008) 1-7

24. A. Jain, R. Balasubramanian, M. P. Srinivasan, Chem. Eng. J. 283 (2016) 789-805

25. X. Xu, Y. Kan, L. Zhao, X. Cao, Env. Pollution 213 (2016) 533-540

26. Y. Yao, B. Gao, M. Inyang, A. R. Zimmerman, X. Cao, P. Pullammanappallil, L. Yang, J. Hazardous Mater. 190 (2011) 501-507

27. M. S. Shafeeyan, W. M. A. W. Daud, A. Houshmand, A. Arami-Niya, Appl. Surf. Sci. 257 (2011) 3936-3942 